\title{
A hybrid algorithm for voltage stability enhancement of distribution systems
}

\author{
Hazim Sadeq Mohsin Al-Wazni, Shatha Suhbat Abdulla Al-Kubragyi \\ Department of Electrical Engineering, Technology University, Baghdad, Iraq
}

\begin{abstract}
Article Info
Article history:

Received Feb 26, 2021

Revised Jun 18, 2021

Accepted Jun 29, 2021

Keywords:

D-STATCOM

HFPSO algorithm

Smart distribution grid

Voltage stability

ABSTRACT

This paper presents a hybrid algorithm by applying a hybrid firefly and particle swarm optimization algorithm (HFPSO) to determine the optimal sizing of distributed generation (DG) and distribution static compensator (D-STATCOM) device. A multi-objective function is employed to enhance the voltage stability, voltage profile, and minimize the total power loss of the radial distribution system (RDS). Firstly, the voltage stability index (VSI) is applied to locate the optimal location of DG and D-STATCOM respectively. Secondly, to overcome the sup-optimal operation of existing algorithms, the HFPSO algorithm is utilized to determine the optimal size of both DG and D-STATCOM. Verification of the proposed algorithm has achieved on the standard IEEE 33-bus and Iraqi 65-bus radial distribution systems through simulation using MATLAB. Comprehensive simulation results of four different cases show that the proposed HFPSO demonstrates significant improvements over other existing algorithms in supporting voltage stability and loss reduction in distribution networks. Furthermore, comparisons have achieved to demonstrate the superiority of HFPSO algorithms over other techniques due to its ability to determine the global optimum solution by easy way and speed converge feature.
\end{abstract}

This is an open access article under the CC BY-SA license.

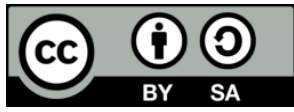

\section{Corresponding Author:}

Hazim Sadeq Mohsin Al-Wazni

Department of Electrical Engineering, Technology University

Industrial Street, Baghdad, Iraq

Email: hazimwazni83@gmail.com

\section{NOMENCLATURE}

$\begin{array}{cl}V_{R} & : \text { The voltage at receiving end bus } \\ V_{S} & : \text { The voltage at sending end bus } \\ V_{R n e w} & : \text { The voltage at receiving end bus after } \\ & \text { compensated } \\ \theta_{\text {new }} & : \text { Phase angle between } V_{R n e w} \text { and } V_{S} \\ \delta & : \text { Phase angle of sending end voltage } \\ \alpha & : \text { Phase angle of Current pass between } \\ & \text { two buses } \\ V_{R, \min } & : \text { Minimum Voltage limit of bus ' } \mathrm{R} \text { ' } \\ V_{R, \max } & : \text { Maximum Voltage limit of bus 'R' } \\ P_{R(R)} & : \text { Real power of DG at bus 'R' } \\ V S I_{R} & : \text { Voltage stability index of node 'R' } \\ A V(x) & : \text { Average of buses voltages } \\ W & : \text { Weight inertia } \\ C_{2,} c_{1} & : \text { Acceleration coefficients } \\ I_{L} & : \text { Current pass between two buses } \\ g b e s t^{t-1} & : \text { Global best size }\end{array}$

\author{
Size of particles \\ Updated size of the particles \\ : Velocities of the particles \\ Updated velocities of the particles \\ Number of iteration \\ The injected current of D-STATCOM \\ Total power losses \\ : Impedance of branch between bus ' $S$ ' and 'R' \\ : Weighting factors of objective functions $\beta \_1$ \\ : Reactive power of D-STATCOM at bus 'R' \\ : Total real loss before insert DG and D- \\ STATCOM \\ : Loss Reduction Index with DG and D- \\ STATCOM \\ : Minimum, maximum injected reactive power \\ limit of compensated bus' $\mathrm{R}^{\prime}$ \\ : Maximum, minimum real power limit of \\ compensated bus 'R'
}




\section{INTRODUCTION}

Nowadays, transmission and distribution power systems are facing a challenge to provide the power demands for more customers with better quality and higher reliability at a lower cost. Such growing demand increasing power transfer through lines which is limited by the thermal, voltage, and stability of lines. Consequently, when the lines are operated near to their critical limits of power angles or voltage limits, any increased demand in this system would results instability like power system oscillation and voltage collapse occurrence which may lead to generator outages and ultimately blackout [1].

Different techniques have been suggested by researchers for solving the voltage system stability issues and minimizing losses in distribution systems. Previosly, system planners are inclined to develop new lines. However, such technique is difficult to implement due to some of the economic and environmental concerns [2], [3]. So, these various restrictions on the construction of new transmission lines have persuaded the power system designers to look for some alternative solutions,so to increase the power system stability and efficiently transmit power over the transmission lines [4].

To minimize the probability of voltage collapse happening and enhance voltage stability as well as improve voltage profile, some researchers have proposed to add capacitors in an optimal location with optimal size by using different optimization techniques such as harmonic search (HS) algorithm [5], dice game optimization (DGO) [6], and modified biogeography based optimization (MBBO) algorithm [7]. However, these shunt capacitors are not capable to constantly produce a variable reactive power and exhibit some of the operational problems like resonance [2]. Such restrictions of the construction of shunt capacitors have persuaded the power system designers to look for some alternative solutions.

Recently, distribution generators (DG) are widely known as "an electric power source connected directly to the distribution network or on the customer side of the meter", that form the key part of the solutions [8]. DGs are known as small distributed generators which are consisted of renewable and nonrenewable power sources. DGs are contributed to the centralized power grids that are managed at the distribution level [9]. The integration of renewable energy sources in the conventional distribution system is becoming valuable and more attractive due to their economic and technical impacts [10]. Many researcher have adopted various types of renewable sources (fuel cell, PV, battery, biomass, wind) [11]-[14]. However, advanced devices are required to control and manage the new smart distribution grids to operate with bidirectional power flow using power electronics and energy storage units [15]. Combining the use of the distributed flexible ac-transmission system (D-FACTS) as a power electronic device with DG in the distribution networks will mitigate the problems of environmental, reliability, and stability issues [2].

The distributed static synchronous compensator (D-STATCOM) is the most important type of shunt-connected D-FACTS device, it is connected directly to low voltage distribution grids without any ancillary components which represents as an efficient shunt capacitors substitute [2]. It acts as a reactive power compensation source, harmonics reduction, power factor correction, and controlling the voltage of the distribution network [16]. Recently, the combination of DG and D-STATCOM was suggested which could compensate for the active and reactive power in smart distribution grids. The optimal location and the capacity of DGs of these sources are some of the main factors of contribution in affecting the improvement of the power quality indices such as the reduction of the distribution systems losses and maintaining the voltage profile within acceptable limits [17].

A DG with D-STATCOM was tested under different conditions to enhance the voltage stability of different load models [2], [18]. Several studies have been presented under the name of metaheuristic techniques such as "whale optimization algorithm (WOA) [17], noval light search algorithm (LSA) [2], gravitational search algorithm (GSA) [19], a combination of genetic algorithm and particle swarm optimization (GA and PSO) [20], grey wolf optimization algorithm (GWOA) [21], vortex searching algorithm [22], imperialist competitive algorithm (ICA) [8], and hybrid genetic and ant colony algorithm [16]" to determine the optimal placement problem of DG and D-STATCOM in smart power systems. Many of the above studies mentioned above have been carried out to locate the optimal location and size problems of DG and D-STATCOM devices separately or simultaneously.

Remarkably, a comprehensive study is lacking in using intelligent algorithms in exploiting the potentials of the DGs with D-STATCOM. Although, several studies have presented under the name of metaheuristic techniques. PSO and general algebraic modeling systems were proposed to solve the sizing and location of single and multiple D-STATCOM in [23]. An artificial fish swarm optimization algorithm (AFSOA) using voltage stability index (VSI) and loss sensitivity factor (LSF) was applied to deduce the size and optimal locations of DGs and D-STATCOM in [24]. 
Further, research on using the VSI and WOA was developed to select the proper location and best size of DG, so to enhance the voltage stability and increase the load-ability through injecting the appropriate active and reactive powers. However, the best DG place is allocating by using the VSI to find the most sensitive buses [25]. The literature clarified that the researchers are continuing to develop intelligent optimization techniques to solve global optimization problems. This paper has proposed to exploit the advantage of firefly algorithm (FA) and PSO as a fast converge optimization algorithm with good-tuning feature, so to easily achieve the global optimum solution for optimal placement and sizing of DG and DSTATCOM device to support the grid's voltage stability as well as enhance voltage profile and minimize power losses.

The motivation of this study focuses on the tabulated results which illustrate the ability of the hybrid firefly and particle swarm optimization algorithm (HFPSO) to determine the optimal placement and sizing of DG and D-STATCOM device, due to its feature to find the global optimum solution. The algorithm is based on a multi-objective HFPSO to minimize the system power losses and voltage profile enhancement as well as increasing the system stability. The verification of the proposed algorithm is achieved on the standard IEEE 33-bus and Iraqi 65-bus radial distribution systems through simulation using MATLAB.

This paper is organized as follows. Section 2 explains the system modeling, While section 3 presents the problem formulation. A hybrid algorithm combining the firefly algorithm and particle swarm optimization is introduced in section 4 . In section 5 , the simulation results of a distribution system under different cases with the proposed algorithm are presented. Furthermore, a performance comparison of the system is then carried out against other existing algorithms in supporting voltage stability and loss reduction in the distribution networks. Finally, section 6 gives concluding remarks on the current work.

\section{SYSTEM MODELLING}

\subsection{D-STATCOM modelling}

D-STATCOM is well-known as an efficient power electronic device control power flow [16], [26]. The basic function of the D-STATCOM is providing reactive power that depends on the reactive power exchange between the AC grid and the D-STATCOM with fast and uninterrupted power [16], [21], [27]. The injected reactive power deduce by (1).

$$
Q_{D-S T A T C O M}=V_{\text {rnew }}\left(I_{D-S T A T C O M}\right)^{*}
$$

Where $I_{D-\text { STATCOM } \angle}\left(\left(\frac{\pi}{2}\right)+\theta_{\text {new }}\right)$ is the injected current by DSTATCOM $V_{\text {Rnew }}=V_{\text {Rnew }} \angle \theta_{\text {new }}$ is the voltage of bus ' $R$ ' after correction. Figure 1(a) shows the single line diagram of two buses of a distribution system with D-STATCOM that is installed in bus ' $\mathrm{R}$ ' Voltage of bus ' $\mathrm{R}$ ' changes from $V_{R}$ to $V_{R \text { Rew }}$ as shown in Figure 1(b).

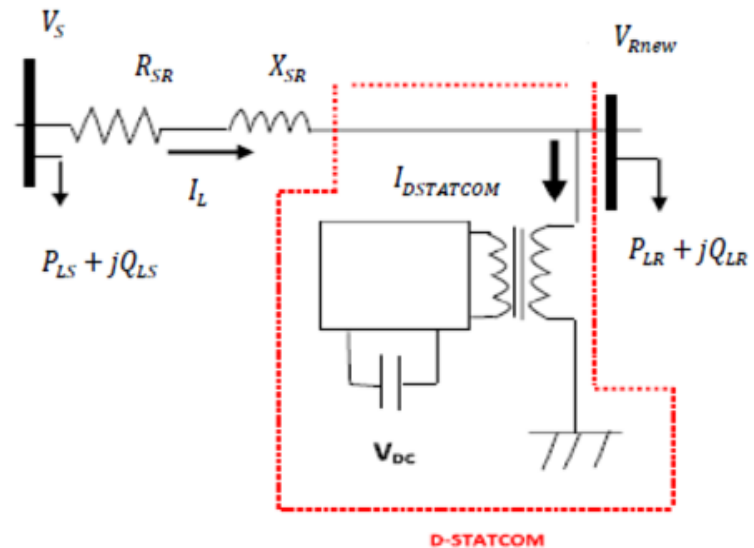

(a)

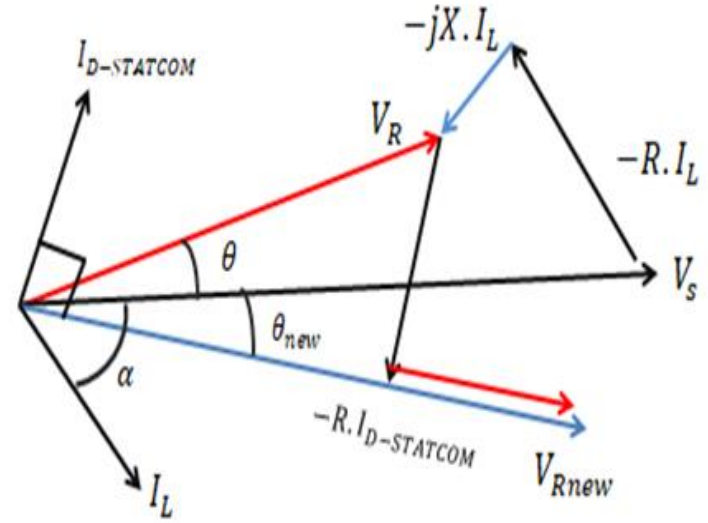

(b)

Figure 1. Single line diagram and the phasor diagram of two buses with D-STATCOM: (a) single line diagram of two buses with D-STATCOM [21], (b) the phasor diagram of two buses with D-STATCOM [21]

$$
V_{\text {Rnew }} \angle \theta_{\text {new }}=V_{S} \angle \delta-\left(R_{S R}+j X_{S R}\right) I_{L} \angle \alpha-\left(R_{S R}+j X_{S R}\right) I_{D-S T A T C O M} \angle\left(\left(\frac{\pi}{2}\right)+\theta_{\text {new }}\right)
$$


DSTATCOM is one of the most efficient D-FACTS devices due to its features like zero resonance, less harmonic distortion, low power losses, low cost, compact size and high regulatory capability [16], [28]. D-STATCOM has been employed as multi-applications at the distribution grids, so to enhance voltage profile, minimize real power loss, improves load ability, and enhances stability [21]. However, the proper location of D-STATCOM is important to minimize the network power loss and subject to the following standard limits [29]:

$$
\text { Voltage limit: } V_{R, \min } \leq V_{R} \leq V_{R, \max }
$$

where $V_{R, \min }$ is the minimum voltage limits of bus ' $\mathrm{R}$ ' and $V_{R, \max }$ is the maximum voltage limits of bus 'R'.

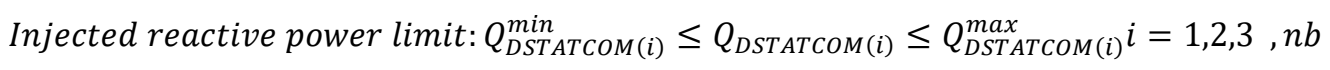

Where $Q_{D S T A T C O M(R)}^{\min }$ is the minimum reactive power limit of the compensated bus ' $\mathrm{R}$ ' and $Q_{D S T A T C O M(R)}^{\max }$ is the maximum reactive power limit of the compensated bus 'R'.

\subsection{Distributed generation (DG)}

DG is described as a small-scale electric power generation that has a capacity of $1 \mathrm{~kW}$ to $100 \mathrm{MW}$ and linked adjacent to the loads. DG consists of renewable and nonrenewable sources such as micro turbines, induction generators, synchronous generators, solar photovoltaic, fuel cells, combustion gas turbines, wind turbines, and other small power generation sources. DG sources are classified into the following four types [22]:

a) DG type one: DG injects real power $(\mathrm{P})$ only

b) DG type two: DG injects both real and reactive power (P and $\mathrm{Q})$

c) DG type three: DG injects real $(\mathrm{P})$ power but absorbs reactive power $(\mathrm{Q})$

d) DG type four: DG injects reactive power $(\mathrm{Q})$ only

The main features of DGs are mitigating the greenhouse effect and using fossil fuel, improve voltage profile, energy security, reliability, stability, power quality, and reduces power losses [8], [9], [29]. Nevertheless, the optimal locations of DGs are also important to improve the system operation characteristics and subject to the following standard limits [30]:

$$
\text { Voltage limit: } V_{R, \min } \leq V_{S} \leq V_{R, \max }
$$

Injected reactive power limit: $P_{R, \min (i)} \leq P_{R(i)} \leq P_{R, \max (i)} i=1,2,3, n b$

where $P_{R, \min (R)}$ is the minimum real power limit of the compensated bus 'R' and $P_{R, \max (R)}$ is the maximum real power limit of the compensated bus 'R'.

\section{PROBLEM FORMULATION}

\subsection{Load flow analysis}

The direct load flow analysis is considered in this paper to find the power losses and voltage profiles of each bus developed for the radial distribution systems. The power-flow equations are written according to Kirchhoff's Current Law, a more detailed explanation of the power flow analysis can be found in [27]. The sample distribution system is shown in Figure 2. The voltage at bus ' $R$ ' is written as in (3):

$$
V_{R}=V_{s}-B_{s} *\left(R_{s R}+j X_{s R}\right)
$$

where $B_{s}$ is the bus-currents to branch-currents matrix. The total power loss of the network is calculated by summing the power losses of all the branch as shown in (4) [2]:

$$
S_{\text {total loss }}=\sum_{s=1}^{\text {no.branch }} P_{\text {loss }}(S, R)+j \sum_{s=1}^{\text {no.branch }} Q_{\text {loss }}(S, R)
$$

where the power loss in a branch between buses 'S 'and ' $R$ ' is identified by using (5) and (6) for real and reactive losses respectively. 


$$
\begin{aligned}
& P_{\text {loss }}(S, R)=\left(\frac{P_{s}^{2}+Q_{s}^{2}}{\left|V_{s}\right|^{2}}\right) * R_{s R} \\
& Q_{\text {loss }}(S, R)=\left(\frac{P_{s}^{2}+Q_{s}^{2}}{\left|V_{s}\right|^{2}}\right) * X_{S R}
\end{aligned}
$$

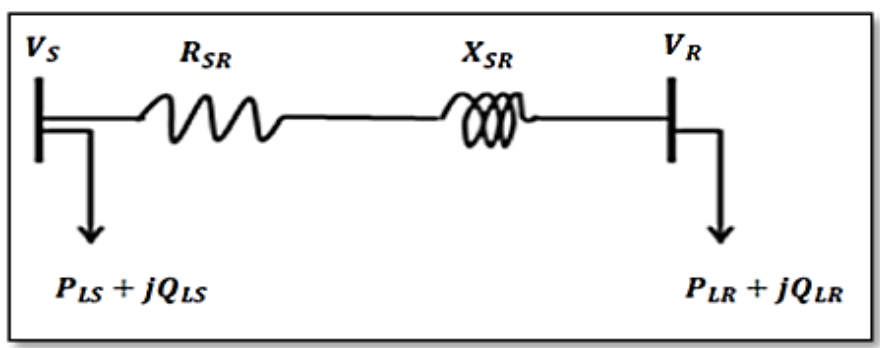

Figure 2. Single line diagram of two buses system [21]

\subsection{Objective function}

The multi-objective function should be modeled carefully to avoid conflicting between various single objective functions. In this paper, the objective function of the proposed algorithm is adopt a number of functions to be optimized simultaneously such as maximize voltage stability index, mitigate the power loss and enhance the bus voltage profile with a weighting factor. The weight factors are considered to determine the priority impact of every single objective function for DG/D-STATCOM interconnection. Due to the fact that, power losses have a greater effect on utilities and represent the major concern in the power system network. Therefore, it should be reduced by selected appropriate weight factors more imperative than the influence voltage stability index and voltage profile. Mathematically, the multi-objective function has as shown in (7):

$$
\operatorname{Minimize}(\text { Fittness })=\min \left(\beta_{1}\left(\Delta P_{T L}^{D G / D S T}\right)+\beta_{2}\left(\frac{1}{A V(x)}\right)+\beta_{3}\left(\frac{1}{\Delta V S I^{D G / D S T}}\right)\right)
$$

where $\Delta P_{T L}^{D G / D S T}$ is the ratio of the total power loss after and before adding DG/D-STATCOM in radial distribution system (RDS) which given by (8) [17].

$$
\Delta P_{T L}^{D G / D S T}=\frac{P_{T L}^{D G / D S T}}{P_{T L}}
$$

$\triangle V S I^{D G / D S T}$ is the ratio of the voltage stability index of weaken bus after and before adding DG/D-STATCOM in RDS which is given by (9) [2].

$$
\Delta V S I^{D G / D S T}=\frac{V S I_{\text {after }}^{D G / D S T}}{V S I_{\text {befor }}}
$$

$A V(x)$ is the average of buses voltages which is given by (10) [15].

$$
A V(x)=\left(\frac{\sum_{i=1}^{n} V_{i}(x)}{n}\right)
$$

$\beta_{1}, \beta_{2}$ and $\beta_{3}$ are the weighting factors of the minimization power loss and maximization AV and VSI respectively which are considered as $(0.7),(0.3)$, and $(0.3)$ respectively.

\subsection{Voltage stability index}

Voltage stability is the ability of a power system to meet the increasing demand and maintain the voltage at all buses in an acceptable limit and to avoid the occurrence of the voltage collapse. The voltage 
collapse is defined as a very low voltage profile in a significant number of the system buses with a sequence of events accompanying voltage instability [1], [31].

The power system security level can be reflected by many possible indices. In this part, the VSI is applied pre-identify to identify the weak buses of radial distribution networks, in order to strengthen these buses and maintain system voltages at an acceptable level. It will add DGs and D-STATCOM in an optimal location. Then, to overcome the sup-optimal operation of the existing algorithms, the HFPSO algorithm is utilized to determine the optimal size of both DG and D-STATCOM. Moreover, the predetermining advantage of the optimal location by using VSI to minimize the search space of the optimization algorithm. The monetary value of voltage stability index can be formulated as relation in (11) [22], [24]:

$$
V S I_{R}=\left|V_{S}\right|^{4}-4\left(P_{R} X_{S R}-Q_{R} R_{S R}\right)^{2}-\left|V_{S}\right|^{4}\left(P_{R} R_{S R}+Q_{R} X_{S R}\right)
$$

where $V S I_{R}$ is the voltage stability index of node 'R' for the distribution system, which is shown in Figure 3.

\section{HYBRID FIREFLY AND PARTICAL SWARM OPTIMIZATION (HFPSO)}

A HFPSO is used in this study so to find the optimum DG and D-STATCOM placement and sizing. The HFPSO is introduced firstly by [32] to solve the optimization problem. The performance of the proposed hybrid optimization algorithm has significant improvements over the standard PSO and FA algorithms due to the combination of the advantages and strengths of PSO and FA, and also because it mitigates the disadvantages of these algorithms. Generally, it provides a fast convergence as PSO feature and easily achieves the global optimum solution as a good-tuning feature of FA [32]. Figure 3 shows the flowchart of the proposed hybrid of FA and PSO.

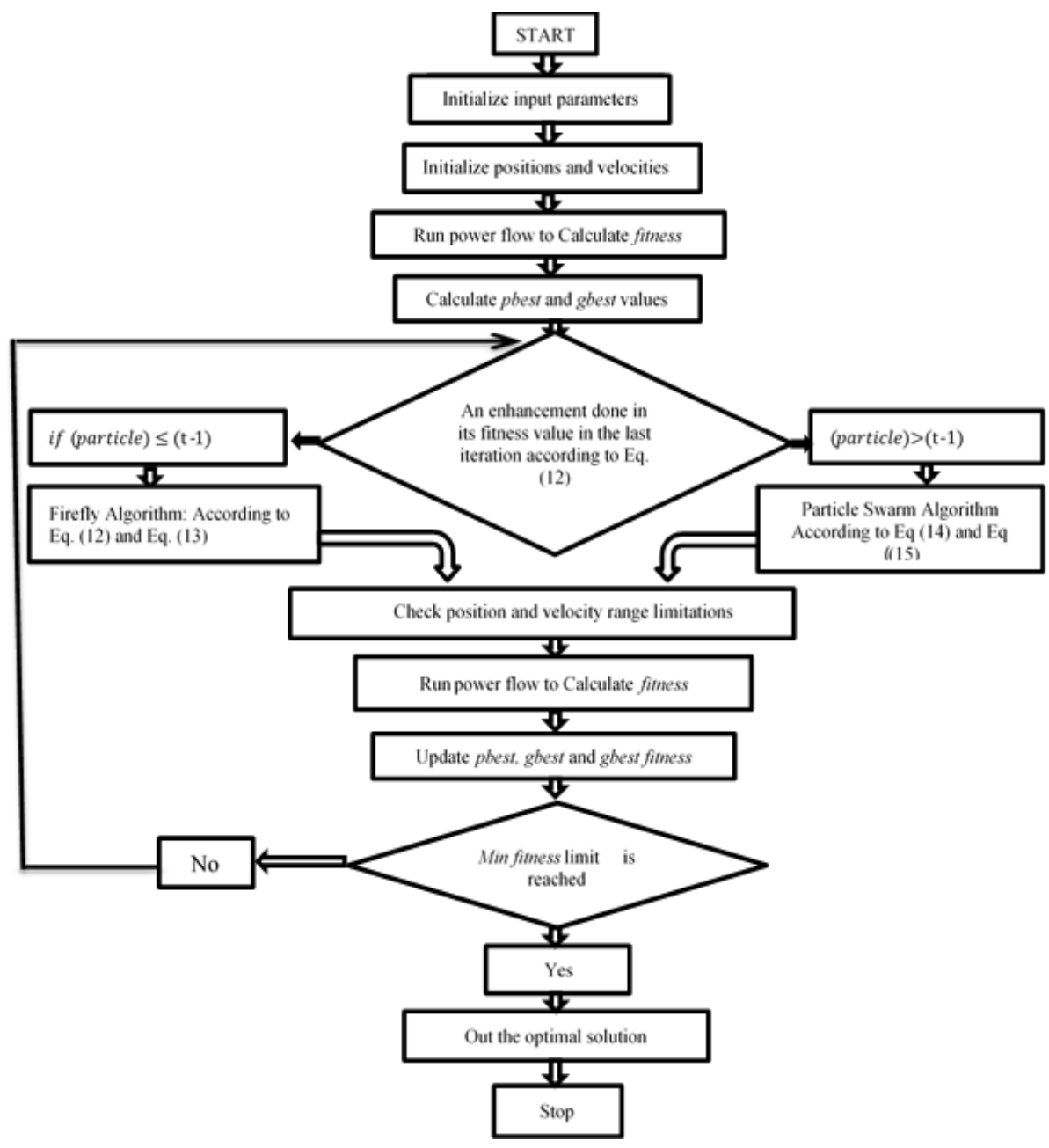

Figure 3. Flowchart of HFPSO algorithm [32] 
To illustrate the HFPSO algorithm, the steps of the algorithm steps are described below:

1. Input the parameters that are used by both algorithms and initialize particles with random positions and velocities. In the considered case, the location of D-STATCOM and DG are generated in a form of vectors as algorithm particles.

2. Run the load flow program to calculate the fitness of each particle according to (7).

3. Calculate the global and personal best particles and then assigned

4. An improvement is done in its fitness value in the last iteration according to (12).

$$
f(i, t)=\left\{\begin{array}{cc}
\text { true }, \text { if fitness }\left(\text { particle }_{i}^{t}\right) & \leq \text { gbest }^{t-1} \\
\text { false. if fitness } \left.^{\text {particle }}{ }_{i}^{t}\right) & >\text { gbest }^{t-1}
\end{array}\right.
$$

5. Save the current position in a temp variable $\left(x_{i-t e m p}\right)$ and calculate the new position and velocity according to (13) and (14).

$$
\begin{aligned}
& x_{i}(t+1)=x_{i}(t)+B_{\circ} e^{-\gamma r^{2} i j}\left(x_{i}(t)-g b e s t^{t-1}\right)+{ }^{\mathrm{a} \epsilon_{i}} \\
& v_{i}(t+1)=x_{i}(t+1)-x_{i-t e m p}
\end{aligned}
$$

6. Start the local search and handle particle by an imitative FA if a particle has a better or equal fitness value than the previous global best, otherwise, PSO continues its standard processes with a particle according to (15) and (16) so to handle this particle.

$$
\begin{aligned}
& V_{i}(t+1)=w V_{i}(t)+c_{1} t_{1}\left(\text { pbest }_{i}(t)-x_{i}(t)\right)+c_{2} t_{2}\left(\text { gbest }_{i}(\mathrm{t})-x_{i}(\mathrm{t})\right) \\
& x_{i}(t+1)=x_{i}(t)+V_{i}(t+1)
\end{aligned}
$$

7. Run the load flow to calculate the fitness of each particle, select the dominant one and consider it as best global fitness if it was better than the previous global fitness.

8. Update the best position of each particle by comparing the new position to the best global position.

9. If the algorithm converges, the optimization process is over. Print the optimal solution, or otherwise, go to step 4.

\section{RESULTS AND DISCUSSION}

To demonstrate the performance of the HFPSO method, a standard IEEE 33-bus RDS and 65-bus Iraqi RDS are used and simulated using the MATLAB. The losses and bus voltage for all the systems are calculated through the direct load flow analysis. The optimal location and sizing of DG and D-STATCOM are obtained by the proposed optimization algorithm HFPSO. To demonstrate the effectiveness of the proposed algorithm, the overall findings/results are compared with other optimization techniques such as; bacterial foraging optimization algorithm (BFOA) [18] and the PSO [10], [33], [34] for four different cases as follows: i) case 1 the system without DG and D-STATCOM, ii) case 2 the system with only DSTATCOM, iii) case 3 the system with only DG and iv) case 4 the system with multi DG and D-STATCOM.

\subsection{3-bus test system}

A bus test radial distribution system is considered in this paper. To show the effectiveness of the proposed method, four different case studies have been tested. The data of the system are taken from [35]. The total load of the system is $3715 \mathrm{~kW}$ and $2300 \mathrm{KVar}$ with the base apparent power and base voltage are $100 \mathrm{MVA}$ and $12.66 \mathrm{kV}$ respectively. The comparative simulation results of the proposed algorithm and other optimization techniques are shown in Table 1 . Firstly, the system without DG and D-STATCOM as a base case is simulated. So, the active power losses, the minimum VSI, and the minimum voltage are $210.77 \mathrm{~kW}, 0.66734$ p.u, and 0.90383 p.u, respectively as indicated in Table 1.

Then, the D-STATCOM is placed at $30^{\text {th }}$ bus as the optimal location (case 2), the total power loss has been reduced to $143.6 \mathrm{~kW}$ and the minimum VSI is enhanced to $0.7355 \mathrm{p} . \mathrm{u}$, while the results obtained in [18] are $144.38 \mathrm{~kW}$ and 0.7228 p.u respectively. In this case, the authors have taken the line data of RDS presented in [36], [37] which differs from the line data considered in this paper but the same line data considered in [27] in case placement D-STATCOM. In case 3, one DG (type one) is optimally placed in the $6^{\text {th }}$, bus with $2720 \mathrm{~kW}$ as an optimal size. The total power loss is reduced to $111.23 \mathrm{~kW}$ and the minimum 
VSI of this system is enhanced to 0.7949 p.u. Clearly, the power loss reduction and VSI enhancement, in this case, are better than other optimization methods as illustrates in Table 1. Finally, in case 4, three DG and three D-STATCOM are placed in the system at optimal locations to reduce the power losses and to improve the minimum VSI of this system. The obtained results are presented in Table 1. The total power loss is reduced to $13.8 \mathrm{~kW}$ and the minimum VSI is enhanced to 0.9415 p.u. It is noticed that the results in case 4 are better than the results of other algorithms. Obviously, the HFPSO gives a good reduction in losses and the voltage profile of the system has been improved noticeably compared to other algorithms. A comparison of the voltage profile, stability voltage index and the total power losses for the four different cases are shown in Figure 4(a), 4(b), and 4(c) respectively.

Table 1. The comparative simulation results

\begin{tabular}{ccccc}
\hline & Variable & HFPSO & BFOA [18] & PSO [10], [33], [34] \\
\hline Case 1 & Ploss (kW) & 210.77 & 210.98 & 210.99 \\
& VSImin (p.u.) & 0.66734 & 0.6610 & 0.6671 \\
Case 2 & Vmin (p.u.) & 0.90383 & 0.9037 & 0.9038 \\
& Size in kVAr (location) & $1300(30)$ & $1102.7(30)$ & $1233(7)$ \\
& Ploss (kW) & 143.6 & 144.38 & 153 \\
& VSImin (p.u.) & 0.7355 & 0.7228 & 0.726 \\
Case 3 & Vmin (p.u.) & 0.9261 & & 0.922 \\
& Size in kW (location) & $2720(6)$ & $2200(6)$ & $2895.1(7)$ \\
& Ploss (kW) & 111.23 & 113.14 & 114.89 \\
& VSImin (p.u.) & 0.7949 & 0.7640 & \\
Case 4 & Vizin (p.u.) & 0.9442 & 0.9368 & 0.9501 \\
& Size in kVAr (location) & $390(12)$ & $400(12)$ & $603.4(8)$ \\
& & $650(24)$ & $350(25)$ & $466.3(22)$ \\
& Size in kW (location) & $840(30)$ & $850(30)$ & $856.7(30)$ \\
& & $870(12)$ & $850(12)$ & $1015.4(9)$ \\
& & $1030(30)$ & $860(30)$ & $851.4(24)$ \\
& & 13.8 & 15.07 & 27.3993 \\
& Ploss (kW) & 0.9415 & 0.9376 & \\
& VSImin (p.u.) & 0.985 & 0.9862 & 0.975 \\
\hline
\end{tabular}

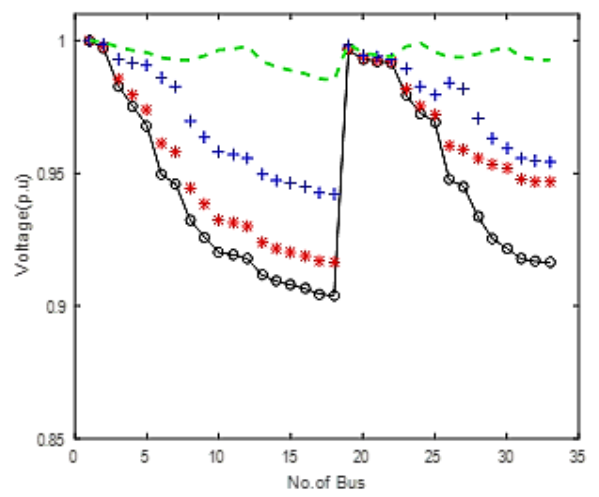

(a)

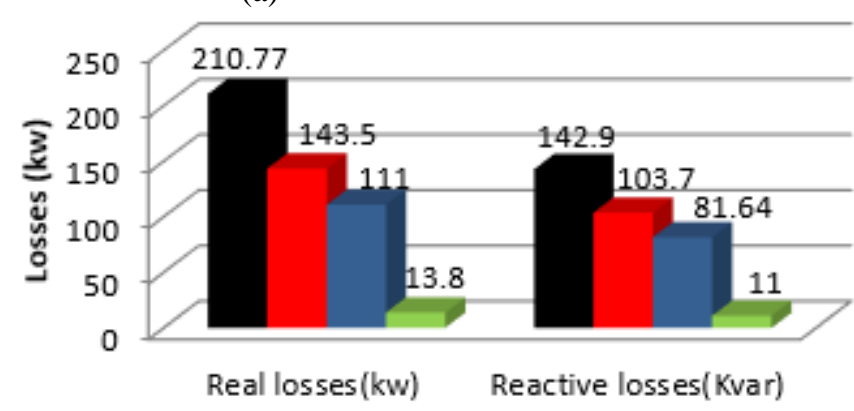

(c)

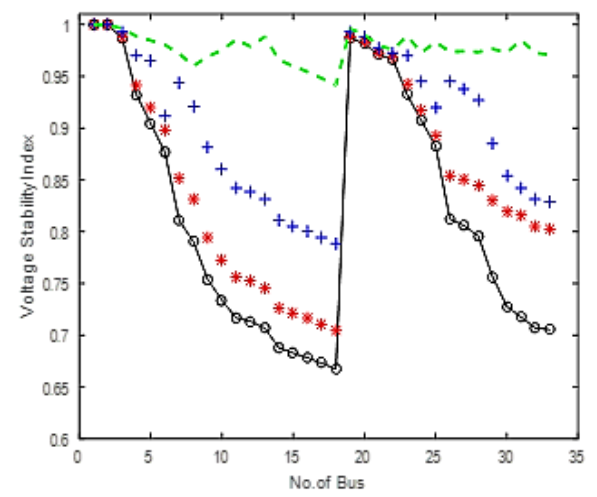

(b)

without DG\&DSTATCOM

with1 DSTATCOM

with 1 DG

with 3 DG\& 3 DSTATCOM

Figure 4. Comparison of results for the four different cases: (a) comparison of voltage profiles for different cases in 33-bus system, (b) comparison of VSI for different cases in 33-bus system, and (c) comparison of line losses for different cases in 33-bus system 


\subsection{The 65-bus system numerical results}

The Iraqi real 65-bus radial distribution system is simulated as a second test system under four different case studies. Figure 5 shows the system's configuration. The system data is given in Table 2 and the results are presented in Table 3. The total load of this RDS is $5669.1 \mathrm{~kW}$ and $3560.6 \mathrm{KVar}$ with base apparent power and base voltage are $100 \mathrm{MVA}$ and $11 \mathrm{kV}$ respectively. The active power losses, the minimum VSI, and the minimum voltage of the base case are $446.2 \mathrm{~kW}, 0.645 \mathrm{p} . \mathrm{u}$, and 0.8962 p.u, respectively.

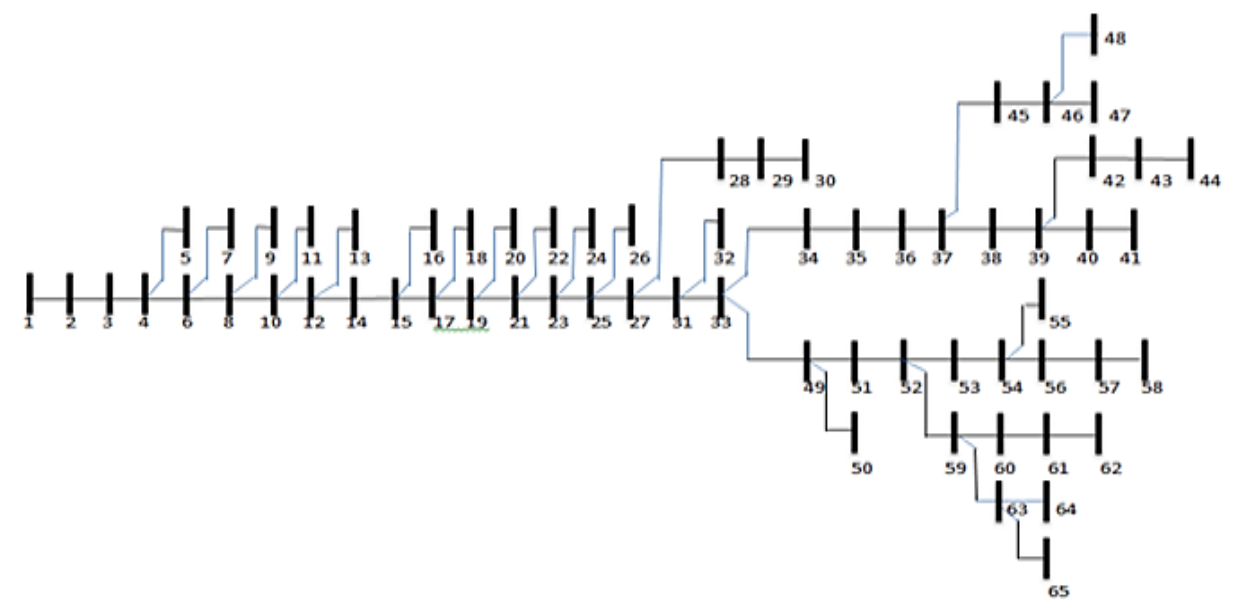

Figure 5. Iraqi real 65-bus configuration

Table 2.65 bus system data

\begin{tabular}{|c|c|c|c|c|c|c|c|c|c|c|c|}
\hline & From & To & R (p.u) & $P_{L}$ & $Q_{L}$ & & To & R (p.u) & X (p.u) & $P_{L}(\mathrm{MW})$ & $Q_{L}(\mathrm{MVAr})$ \\
\hline 1 & 1 & 2 & 0.216363 & (MW) & (MVAr) & 33 & 34 & 0.006175 & 0.007538 & 0.1700 & 0.1054 \\
\hline 2 & 2 & 3 & 0.18478 & 0.1063 & 0.0659 & 34 & 35 & 0.045125 & 0.055081 & 0.1063 & 0.0659 \\
\hline 3 & 3 & 4 & 0.159363 & 0.1063 & 0.0659 & 35 & 36 & 0.032063 & 0.039137 & 0.1063 & 0.0659 \\
\hline 4 & 4 & 5 & 0.06318 & 0.0 & 0.000 & 36 & 37 & 0.030875 & 0.037687 & 0.0 & 0.000 \\
\hline 5 & 4 & 6 & 0.025650 & 0.1700 & 0.1054 & 37 & 38 & 0.046550 & 0.056820 & 0.1063 & 0.0659 \\
\hline 6 & 6 & 7 & 0.011400 & 0 & 0 & 38 & 39 & 0.015200 & 0.018554 & 0.0 & 0.0 \\
\hline 7 & 6 & 8 & 0.077663 & 0.1063 & 0.0659 & 39 & 40 & 0.056763 & 0.069286 & 0.1700 & 0.1054 \\
\hline 8 & 8 & 9 & 0.004750 & 0.0 & 0.00 & 40 & 41 & 0.018763 & 0.022902 & 0.0 & 0.0 \\
\hline 9 & 8 & 10 & 0.073625 & 0.1063 & 0.0659 & 41 & 42 & 0.021138 & 0.025801 & 0.1063 & 0.0659 \\
\hline 10 & 10 & 11 & 0.022325 & 0.0 & 0.000 & 42 & 43 & 0.045600 & 0.055661 & 0.1700 & 0.1054 \\
\hline 11 & 10 & 12 & 0.024938 & 0.1063 & 0.0659 & 43 & 44 & 0.022088 & 0.026961 & 0.1063 & 0.0659 \\
\hline 12 & 12 & 13 & 0.066025 & 0.0 & 0.000 & 44 & 45 & 0.026363 & 0.032179 & 0.1700 & 0.1054 \\
\hline 13 & 12 & 14 & 0.032300 & 0.1700 & 0.1054 & 45 & 46 & 0.037525 & 0.045804 & 0.0 & 0.00 \\
\hline 14 & 14 & 15 & 0.030875 & 0.1700 & 0.1054 & 46 & 47 & 0.055813 & 0.068127 & 0.1063 & 0.0659 \\
\hline 15 & 15 & 16 & 0.031588 & 0.0 & 0.0 & 47 & 48 & 0.007600 & 0.009277 & 0.1063 & 0.0659 \\
\hline 16 & 15 & 17 & 0.089538 & 0.1700 & 0.1054 & 48 & 49 & 0.021375 & 0.026091 & 0.0 & 0.000 \\
\hline 17 & 17 & 18 & 0.017100 & 0.0 & 0.0 & 49 & 50 & 0.009975 & 0.012176 & 0.1063 & 0.0659 \\
\hline 18 & 17 & 19 & 0.014725 & 0.1063 & 0.0659 & 50 & 51 & 0.029688 & 0.036238 & 0.1700 & 0.1054 \\
\hline 19 & 19 & 20 & 0.015675 & 0.0 & 0.000 & 51 & 52 & 0.006413 & 0.007827 & 0.0 & 0.000 \\
\hline 20 & 19 & 21 & 0.095238 & 0.1063 & 0.0659 & 52 & 53 & 0.081225 & 0.099146 & 0.1700 & 0.1054 \\
\hline 21 & 21 & 22 & 0.121838 & 0.0 & 0.0 & 53 & 54 & 0.016150 & 0.019713 & 0.0 & 0.000 \\
\hline 22 & 21 & 23 & 0.113050 & 0.1700 & 0.1054 & 54 & 55 & 0.018525 & 0.022612 & 0.1700 & 0.1054 \\
\hline 23 & 23 & 24 & 0.016388 & 0.0 & 0.0 & 55 & 56 & 0.018763 & 0.022902 & 0.1700 & 0.1054 \\
\hline 24 & 23 & 25 & 0.011400 & 0.1700 & 0.1054 & 56 & 57 & 0.002850 & 0.003479 & 0.1063 & 0.0659 \\
\hline 25 & 25 & 26 & 0.001663 & 0.0 & 0.0 & 57 & 58 & 0.013538 & 0.016524 & 0.1063 & 0.0659 \\
\hline 26 & 25 & 27 & 0.027550 & 0.1063 & 0.0659 & 58 & 59 & 0.012588 & 0.015365 & 0.0 & 0.00 \\
\hline 27 & 27 & 28 & 0.008550 & 0.0 & 0.0 & 59 & 60 & 0.009500 & 0.011596 & 0.1063 & 0.0659 \\
\hline 28 & 28 & 29 & 0.011638 & 0.1063 & 0.0659 & 60 & 61 & 0.050113 & 0.061169 & 0.1700 & 0.1054 \\
\hline 29 & 29 & 30 & 0.020900 & 0.1700 & 0.1054 & 61 & 62 & 0.026125 & 0.031889 & 0.1063 & 0.0659 \\
\hline 30 & 27 & 31 & 0.015675 & 0.1700 & 0.1054 & 62 & 63 & 0.022800 & 0.027830 & 0.0 & 0.000 \\
\hline 31 & 31 & 32 & 0.021613 & 0.0 & 0.0 & 63 & 64 & 0.021138 & 0.025801 & 0.1700 & 0.1054 \\
\hline 32 & 31 & 33 & 0.069113 & 0.1700 & 0.1054 & 64 & 65 & 0.024938 & 0.030439 & 0.1700 & 0.1054 \\
\hline
\end{tabular}

It is depicted from Table 3 the total power loss is reduced to $300.3 \mathrm{~kW}$ and the minimum VSI is enhanced to 0.7941 p.u after D-STATCOM is placed at the $33^{\text {th }}$ bus as the optimal location in case 2 . While 
in case 3 , one DG (type one) is optimally placed in the $33^{\text {th }}$ bus with $5020 \mathrm{~kW}$ as the optimal size. The total power loss is reduced to $122 \mathrm{~kW}$ and the minimum VSI of this system is enhanced to 0.8367 p.u. In case 4 , both three DG and one D-STATCOM are installed at optimal locations to reduce the power losses and to improve the minimum VSI of this system. The obtained results are presented in Table 3 . However, the total power loss is reduced to $12.2 \mathrm{~kW}$ and the minimum VSI is enhanced to 0.9707 p.u after a multi DG and DSTATCOM are placed at the optimal locations. A comparison of the voltage profile, stability voltage index, and the total power losses for the four different cases are shown in Figure 6(a), 6(b), and 6(c) respectively.

Table 3. 65-bus numerical results

\begin{tabular}{ccccc}
\hline & Case 1 & Case 2 & Case 3 & Case 4 \\
\hline Size in MVAr (location) & & $3.34(33)$ & & $2.77(33)$ \\
Size in MW (location) & & & $5.02(33)$ & $3.96(34)$ \\
& & & & $0.39(39)$ \\
& & & & $1.62(3)$ \\
$P$ loss (kw) & 446.2 & 300.3 & 122 & 12.2 \\
$Q$ loss (kvar) & 544.6 & 367 & 148.9 & 14.9 \\
VSImin (p.u.) & 0.645 & 0.7941 & 0.8367 & 0.9707 \\
Vmin (p.u.) & 0.8962 & 0.9440 & 0.9564 & 0.9926 \\
\hline
\end{tabular}

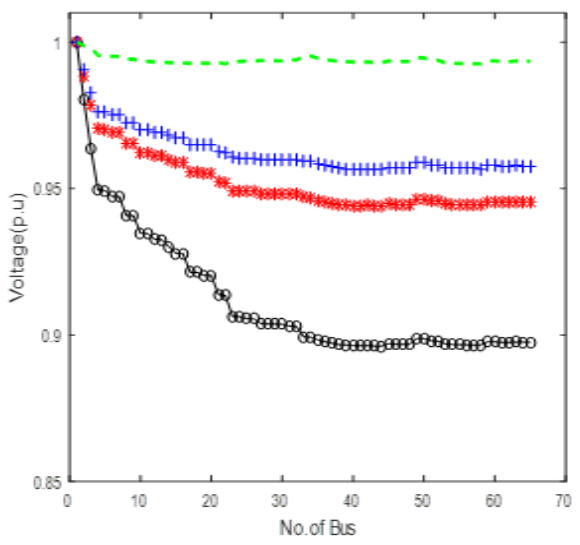

(a)

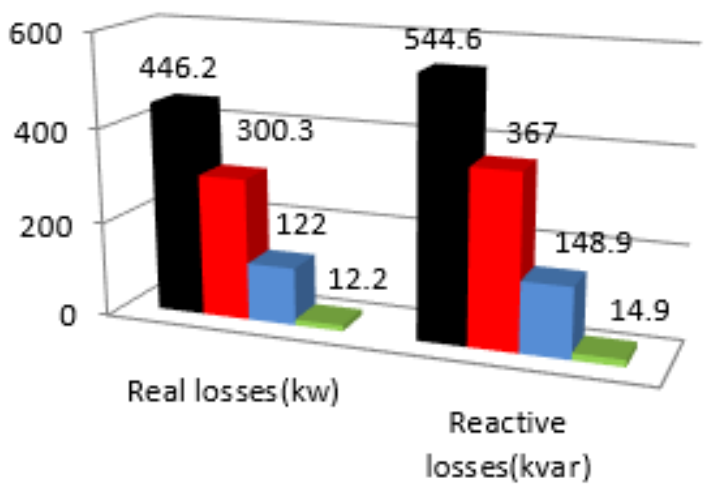

(c)

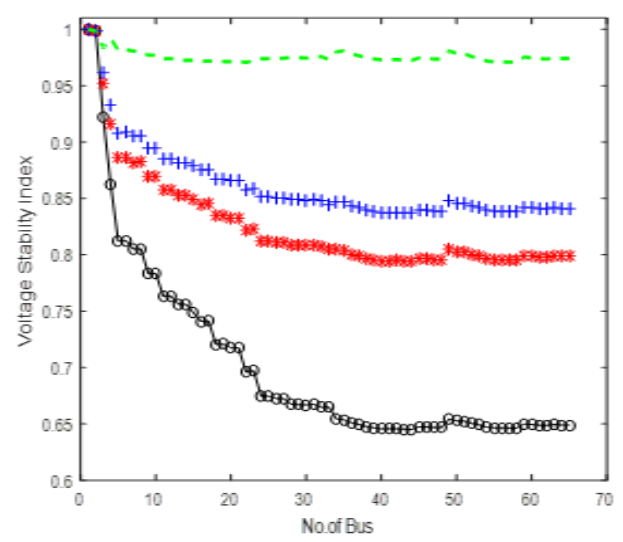

(b)

without DG \& DSTATCOM

with one DSTATCOM

with one DG

with three DG \& one DSTATCOM

Figure 6. Comparison of results losses for the four different cases: (a) comparison of voltage profiles for different cases in Iraqi 65-bus system, (b) comparison of VSI for different cases in Iraqi 65-bus system, and (c) comparison of line losses for different cases in Iraqi 65-bus system

\section{CONCLUSION}

In this paper, a new optimization technique based on HFPSO has been proposed to enhance the system stability of smart distribution grids. The main advantage of the proposed algorithm is to combine the advantages and strengths of PSO and FA and to mitigate the disadvantages of these algorithms. HFPSO is employed to solve a multi-objective function including voltage stability enhancement and minimizing the 
total power loss by finding the optimal locations and sizes of DG and D-STATCOM in the power distribution system. Actually, The effectiveness of the proposed algorithm has been tested on two power systems. Besides, the overall results were, compared with some other optimization techniques such as BFOA and PSO under four different cases. Comprehensive simulation results show that the proposed HFPSO algorithm achieves significant improvements compared to other optimization algorithms in supporting voltage stability and in minimizing the power losses in distribution networks. Generally, HFPSO provides a fast convergence as PSO feature and easily achieves the global optimum solution as a good-tuning feature of the firefly algorithm. Furthermore, it could be concluded that the HFPSO would simplify the use, as an intelligent realtime tool with any large distribution system.

\section{REFERENCES}

[1] N. Ghaffarzadeh, H. Marefatjo, and I. Soltani, "Investigation and comparison of the effect of facts devices, capacitors and lines reactance variations on voltage stability improvement and loadability enhancement in two area power system," International Journal of Applied Power Engineering (IJAPE), vol. 1, no. 3, pp. 145-158, 2012, doi: 10.11591/ijape.v1i3.1618.

[2] Y. Thangaraj and R. Kuppan, "Multi-objective simultaneous placement of DG and DSTATCOM using novel lightning search algorithm," Journal of Applied Research and Technology, vol. 15, no. 5, pp. 477-491, 2017, doi: 10.1016/j.jart.2017.05.008.

[3] R. H. Al-Rubayi and S. S. A. Alhalim, "Stability improvement of the (400 kV) Iraqi grid using the best FACTS devices," Engineering and Technology Journal, vol. 33, no. 7, pp. 1598-1618, 2015.

[4] Q. W. Ali and A. U1 Asar, "Smart power transmission system using FACTS device," International Journal of Applied Power Engineering (IJAPE), vol. 2, no. 2, pp. 61-70, 2013, doi: 10.11591/ijape.v2i2.1606.

[5] M. Suneetha, R. Srinivasa Rao, and B. Subramanyam, "Implement the harmonic search algorithm with optimum location of capacitors sizing and dispatchable DGs to control the reactive power on interconnected bus system," Journal of Advanced Research in Dynamical and Control Systems, vol. 11, no. 1, pp. 880-889, 2019, doi: 10.11591/ijra.v7i3.pp149-158.

[6] M. Dehghani, Z. Montazeri, O. P. Malik, K. Al-Haddad, J. M. Guerrero, and G. Dhiman, "A new methodology called dice game optimizer for capacitor placement in distribution systems," Electrical Engineering amd Electromechanics, vol. 2020, no. 1, pp. 61-64, 2020, doi: 10.20998/2074-272x.2020.1.10.

[7] H. F. Kadom, A. N. Hussain, and W. K. S. Al-Jubori, "Dual technique of reconfiguration and capacitor placement for distribution system," International Journal of Electrical and Computer Engineering (IJECE), vol. 10, no. 1, pp. 80-90, 2020, doi: 10.11591/ijece.v10i1.pp80-90.

[8] N. Ghaffarzadeh, M. Akbari and A. Khanjanzadeh, "Distributed generation allocation to improve steady state voltage stability of distribution networks using imperialist competitive algorithm," International Journal of Applied Power Engineering (IJAPE), vol. 2, no. 2, pp. 71-78, 2013, doi: 10.11591/ijape.v2.i2.pp71-78.

[9] A. H. Kadam, K. Unni, and S. Thale, "Performance analysis of voltage stability against sudden load changes in voltage controlled inverters for distributed generation," International Journal of Applied Power Engineering (IJAPE), vol. 3, no. 1, pp. 33-40, 2014, doi: 10.11591/ijape.v3.i1.pp33-40.

[10] A. Lasmari, M. Zellagui, R. Chenni, S. Semaoui, C. Z. El-Bayeh, and H. A. Hassan, "Optimal energy management system for distribution systems using simultaneous integration of PV-based DG and DSTATCOM units," Energetika, vol. 66, no. 1, pp. 1-14, 2020, doi: 10.6001/energetika.v66i1.4294.

[11] M. B. Eteiba, S. Barakat, M. M. Samy, and W. I. Wahba, "Optimization of an off-grid PV/Biomass hybrid system with different battery technologies," Sustainable Cities and Society, vol. 40, pp. 713-727, 2018, doi: 10.1016/j.scs.2018.01.012.

[12] C. Mokhtara, B. Negrou, N. Settou, B. Settou, and M. M. Samy, "Design optimization of off-grid hybrid renewable energy systems considering the effects of building energy performance and climate change: Case study of Algeria," Energy, vol. 219, pp. 119605, 2021, doi: 10.1016/j.energy.2020.119605.

[13] M. M. Samy and S. Barakat, "Hybrid invasive weed optimization - particle swarm optimization algorithm for biomass/PV microgrid power system," 2019 21st International Middle East Power Systems Conference (MEPCON), 2019, pp. 377-382, doi: 10.1109/MEPCON47431.2019.9008156.

[14] M. M. Samy, M. I. Mosaad, and S. Barakat, "Optimal economic study of hybrid PV-wind-fuel cell system integrated to unreliable electric utility using hybrid search optimization technique," International Journal of Hydrogen Energy, vol. 46, no. 20, pp. 1121711231, 2021, doi: 10.1016/j.ijhydene.2020.07.258.

[15] S. Ganesh and R. Kanimozhi, "Meta-heuristic technique for network reconfiguration in distribution system with photovoltaic and D-STATCOM," IET Generation, Transmission and Distribution, vol. 12, no. 20, pp. 4524-4535, 2018, doi: 10.1049/ietgtd.2018.5629.

[16] A. Bagherinasab, M. Zadehbagheri, S. A. Khalid, M. Gandomkar, and N. A. Azli, "Optimal placement of D-STATCOM using hybrid genetic and ant colony algorithm to losses reduction," International Journal of Applied Power Engineering (IJAPE), vol. 2, no. 2, pp. 53-60, 2013, doi: 10.11591/ijape.v2i2.2408.

[17] T. Yuvaraj, K. R. Devabalaji, and S. B. Thanikanti, "Simultaneous allocation of DG and DSTATCOM using whale optimization algorithm," Iranian Journal of Science and Technology, Transactions of Electrical Engineering, vol. 44, no. 2, pp. 879-896, 2020, doi: 10.1007/s40998-019-00272-w.

[18] K. R. Devabalaji and K. Ravi, "Optimal size and siting of multiple DG and DSTATCOM in radial distribution system using bacterial foraging optimization algorithm," Ain Shams Engineering Journal, vol. 7, no. 3, pp. 959-971, 2016, doi: 10.1016/j.asej.2015.07.002.

[19] A. K. Arya, A. Kumar, and S. Chanana, "Assessment of deployment of DGs and D-STATCOMs in distribution network using gravitational search algorithm," International Journal of Recent Technology and Engineering (IJRTE), vol. 8, no. 5, pp. 119-127, 2020, doi: 10.35940/ijrte.d9009.018520.

[20] M. H. Moradi and M. Abedini, "A combination of genetic algorithm and particle swarm optimization for optimal DG location and sizing in distribution systems," International Journal of Electrical Power and Energy Systems, vol. 34, no. 1, pp. 66-74, 2012, doi: 10.1016/j.ijepes.2011.08.023.

[21] S. F. Mekhamer, R. H. Shehata, A. Y. Abdelaziz, and M. A. Al-Gabalawy, "Enhancing radial distribution system performance by optimal placement of DSTATCOM," International Journal of Electrical and Computer Engineering (IJECE), vol. 10, no. 3, pp. 2850-2860, 2020, doi: 10.11591/ijece.v10i3.pp2850-2860.

Int J Elec \& Comp Eng, Vol. 12, No. 1, February 2022: 50-61 
[22] Y. Latreche, H. R. E. H. Bouchekara, M. S. Javaid, M. M. Aman, H. Mokhlis, and F. Kerrour, "Optimal incorporation of multiple distributed generation units based on a new system maximum loadability computation approach and vortex searching algorithm," International Journal of Applied Power Engineering (IJAPE), vol. 8, no. 2, pp. 186-208, 2019, doi: 10.11591/ijape.v8.i2.pp186208.

[23] V. V. S. N. Murty and A. Kumar, "Impact of D-STATCOM in distribution systems with load growth on stability margin enhancement and energy savings using PSO and GAMS," International Transactions on Electrical Energy Systems, vol. 28, no. 11, pp. 1-24, 2018, doi: 10.1002/etep.2624.

[24] S. R. Salkuti, "Optimal location and sizing of DG and D-STATCOM in distribution networks," Indonesian Journal of Electrical Engineering and Computer Science (IJEECS), vol. 16, no. 3, pp. 1107-1114, 2019, doi: 10.11591/ijeecs.v16.i3.pp1107-1114.

[25] A. Selim, S. Kamel, L. Nasrat, and F. Jurado, "Voltage stability assessment of radial distribution systems including optimal allocation of distributed generators," International Journal of Interactive Multimedia and Artificial Intelligence, vol. 6, no. 1, pp. 32-40, 2020, doi: 10.9781/ijimai.2020.02.004.

[26] K. Rabyi and H. Mahmoudi, "Energy storage of DFIG based wind farm using D-STATCOM," International Journal of Electrical and Computer Engineering (IJECE), vol. 9, no. 2, pp. 761-770, 2019, doi: 10.11591/ijece.v9i2.pp761-770.

[27] S. Devi and M. Geethanjali, "Optimal location and sizing determination of distributed generation and DSTATCOM using particle swarm optimization algorithm," International Journal of Electrical Power and Energy Systems, vol. 62, pp. 562-570, 2014, doi: 10.1016/j.ijepes.2014.05.015.

[28] D. K. Rukmani et al., "A new approach to optimal location and sizing of DSTATCOM in radial distribution networks using bioinspired cuckoo search algorithm," Energies, vol. 13, no. 18, 2020, doi: 10.3390/en13184615.

[29] O. Garfi, H. Aloui, and N. Chaker, "Impacts of photovoltaic power source intermittence on a distribution network," International Journal of Electrical and Computer Engineering (IJECE), vol. 9, no. 6, pp. 5134-5142, 2019, doi: 10.11591/ijece.v9i6.pp51345142 .

[30] S. Y. Reddy, D. S. Reddy, and G. K. Rao, "Optimal siting and sizing of solar power sources in interconnection grid system," International Journal of Applied Power Engineering (IJAPE), vol. 5, no. 1, pp. 1-13, 2016, doi: 10.11591/ijape.v5.i1.pp1-13.

[31] I. I. Ali and M. N. Mohsen, "Enhancement voltage stability of the Iraqi ower grid using shunt FACTs devices," Engineering and Technology Journal, vol. 34, no. 13, pp. 2527-2550, 2016.

[32] İ. B. Aydilek, "A hybrid firefly and particle swarm optimization algorithm for computationally expensive numerical problems," Applied Soft Computing, vol. 66, pp. 232-249, 2018, doi: 10.1016/j.asoc.2018.02.025

[33] A. Zeinalzadeh, A. Estebsari and A. Bahmanyar, "Simultaneous optimal placement and sizing of DSTATCOM and parallel capacitors in distribution networks using multi-objective PSO," 2019 IEEE Milan PowerTech, 2019, pp. 1-6, doi: 10.1109/PTC.2019.8810577.

[34] M. M. Aman, G. B. Jasmon, A. H. A. Bakar, and H. Mokhlis, "A new approach for optimum DG placement and sizing based on voltage stability maximization and minimization of power losses," Energy Conversion and Management, vol. 70, pp. 202-210, 2013, doi: 10.1016/j.enconman.2013.02.015.

[35] L. F. Grisales-Noreña, D. G. Montoya, and C. A. Ramos-Paja, "Optimal sizing and location of distributed generators based on PBIL and PSO techniques,” Energies, vol. 11, no. 4, pp. 1-27, 2018, doi: 10.3390/en11041018.

[36] M. Soliman, A. Y. Abdelaziz, and R. M. El-Hassani, "Distribution power system reconfiguration using whale optimization algorithm," International Journal of Applied Power Engineering (IJAPE), vol. 9, no. 1, pp. 48-57, 2020, doi: 10.11591/ijape.v9.i1.pp48-57.

[37] I. I. Ali and O. Y. Saeed, "Optimal reconfiguration and distributed generation placement in Baghdad distribution sector," Engineering and Technology Journal, vol. 36, no. 3, pp. 333-343, 2018, doi: 10.30684/etj.36.3a.13.

\section{BIOGRAPHIES OF AUTHORS}

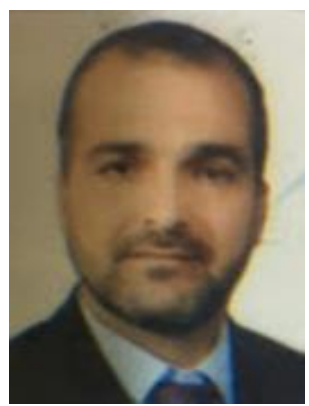

Hazim Sadeq Mohsin Al-Wazni (iD) 81 SC P was born in 1981. He received his B.Sc. degree in Electrical Engineering from University of Babylon, Iraq in 2003. Presently he is pursuing M.Sc. In Electrical Power Engineering in Department of Electrical Engineering at Technology University, Iraq. He has more than 16 years of experience in mantainus of electrical distribution networks. His major scientific interest is focused on optimal location of DG and D-STATCOM devices, modelling and simulation of distribution power system. He can be contacted at email: hazimwazni83@gmail.com.

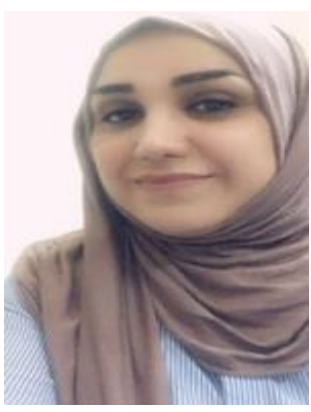

Shatha Suhbat Abdulla Al-Kubragyi (iD $8 \mathrm{~S}$ SC P received her B.Sc. and M.Sc degree in Electrical and Electronic Engineering from University of Technology, Baghdad, Iraq, in 2000 and 2003, respectively. She was awarded a Ph.D. degree from University of Cranfield, UK in 2018. Since 2005, she has been a Lecturer in Electrical Engineering in the Department of Engineering at the University of Technology. Her research interests includes power system analysis, microgrids, renewable energy technologies, FACTS devices, and power system operation and control. She can be contacted at email: Shatha.S.Abdulla@uotechnology.edu.iq. 